\title{
ESTRATÉGIAS INTEGRADAS DE REGENERAÇÃO EM REGIÕES INDUSTRIAIS: uma aproximação com a conjuntura pós-década de 1990 no Sul F́luminense
}

\author{
Raphael Jonathas da Costa Lima*
}

\begin{abstract}
A proposta do artigo é discutir a constituição de novos arranjos institucionais em regiões de perfil industrial, caracterizadas pela presença de setores como a siderurgia e a indústria automobilística. A análise recai sobre iniciativas forjadas em contextos economicamente deprimidos por processos de saída e fechamento de indústrias, reestruturação produtiva e downsizing. O foco está em descrever estratégias e mobilizações cunhadas no seio de organizações públicas e privadas orientadas sob a perspectiva de revitalização dessas áreas degradadas. A discussão aborda a conjuntura do Sul Fluminense, região que viu reforçado, nos últimos anos, um discurso pró-regionalização e cooperação entre seus municípios. $\mathrm{O}$ artigo indica que a região progressivamente se segmenta entre uma extensão em fase de expansão, puxada pela indústria automobilística, e outra estagnada pela dependência frente à atividade de um grande agente econômico. Conclui-se que isso termina instituindo limitações estruturais e comprometendo os planos de um desenvolvimento mais integrado da região.

PALAVRAS-CHAVE: Concertação. Desenvolvimento regional. Governance. Reestruturação produtiva. Revitalização.
\end{abstract}

\section{INTRODUÇÃO}

Este artigo discute a formação de canais de governança econômica e política em regiões de perfil predominantemente industrial, deprimidas por crises provocadas pela saída ou reestruturação de unidades produtivas. O objetivo é descrever estratégias recentes de reorganização regional sob a ótica da construção de novos arranjos institucionais, utilizando como referência a região Sul Fluminense. Discutir-se-á se essas iniciativas, de fato, sinalizam o encaminhamento de um novo desenho institucional em uma região que, nos últimos anos, experimenta um crescimento escorado em novas plantas industriais instaladas nos municípios de Resende e Porto Real, provocando, entre outros efeitos, o deslocamento das atividades sindicais antes quase exclusivamente concentradas no município de Volta Redonda, o qual foi

\footnotetext{
* Doutor em Sociologia. Professor do Instituto de Ciências Humanas e Sociais de Volta Redonda (ICHS), Universidade Federal Fluminense (UFF).

Rua Desembargador Ellis Hermydio, 783, sala 307, Aterrado. Volta Redonda - Rio de Janeiro - Brasil raphaeljonathas@gmail.com
}

seriamente afetado pela privatização da tradicional Companhia Siderúrgica Nacional (CSN), em 1993.

A discussão remete ao debate acerca de iniciativas confeccionadas em contextos afetados por processos de desindustrialização e pelos efeitos negativos da globalização. Serão destacadas, assim, experiências de cooperação que orientaram a revitalização de antigas áreas industriais degradadas, uma vez caracterizadas pela presença de setores economicamente significativos, como siderurgia e indústria automobilística. Parcerias, coalizões, redes sociopolíticas e mecanismos de governança regionalmente elaborados agiram positivamente na recuperação de alguns contextos de crise, e contaram com o engajamento de diversos atores produtivos e políticos, entre eles empresários, trabalhadores e lideranças comunitárias. Construção de planejamentos estratégicos regionais, constituição de projetos de desenvolvimento sustentável e de requalificação da mão de obra disponível, após a saída ou fechamento de empresas, foram algumas iniciativas forjadas em regiões como o ABC paulista, a qual atravessou forte crise entre o final dos anos 1980 e о início dos anos 1990. 
A presente discussão tem como finalidade: apresentar algumas das recentes tentativas de implementação de mecanismos de governança regional (agências, fóruns etc.) identificadas na região fluminense; verificar como tem funcionado a cooperação entre novos e antigos agentes do desenvolvimento econômico da região; identificar se a articulação entre esses agentes indica, de fato, o encaminhamento de um novo desenho institucional para o Médio Paraíba; e indagar sobre limites e possibilidades de sucesso de um experimento desse porte em uma região onde o binômio Volta Redonda/ CSN ainda preserva grande domínio político, tendendo a enviesar propostas de escala coletiva a favor das preocupações de ordem municipal.

Para auxiliar na contextualização dos eventos descritos a seguir, o artigo fará uso de entrevistas realizadas entre os anos de 2008 e 2009 com secretários de planejamento e de desenvolvimento dos municípios de Barra Mansa e Volta Redonda, e com o superintendente executivo da Agência de Desenvolvimento do Médio Paraíba (ADEMP). E, com o intuito de ilustrar eventos que tangenciaram a discussão aqui colocada, foram utilizadas matérias jornalísticas que ajudam a caracterizar o cenário de crise instalada durante a década de 1990. Com base nesses subsídios empíricos, pretendese reforçar o argumento segundo o qual história, instituições locais e capacidade de agentes políticos, econômicos e sociais em empreender projetos coletivos, bem como em articular parcerias, fazem do desenvolvimento regional um processo com particularidades, segundo a esfera subnacional analisada. No caso do Sul Fluminense, fenômenos como a globalização são fundamentais para a compreensão das mudanças pelas quais a região vem passando, desde a privatização da CSN. Porém é importante ressaltar suas especificidades, seus recursos sociopolíticos e seus padrões de associativismo como partes fundamentais da interpretação acerca do seu processo de desenvolvimento. Por outro lado, é provável que a região, ao tentar construir um novo arranjo institucional, tenha encontrado limitações estruturais que contribuíram para minar por dentro o projeto de integração estimulado por autoridades políticas e empresariais de Volta Redonda e Barra Mansa.

Este texto se desdobra em duas seções. A primeira apresenta o debate sobre a democratização do processo de desenvolvimento regional com o foco direcionado para contextos geográficos específicos, que se caracterizaram pelos esforços de reconversão da sua matriz de desenvolvimento ao abdicarem da condição quase monopolista de setores tradicionais como a siderurgia. Aqui se coloca o envolvimento de segmentos da sociedade civil em diálogo com o Estado e os setores produtivos, e sob a alça de instituições e canais de governança regional. E, basicamente, propõe-se ressaltar a peculiaridade das estruturas locais, suas trajetórias e seu conjunto de relações de poder, bem como a habilidade dos atores locais em interferir nas dinâmicas locacionais. Já na segunda seção do artigo, é descrito, de forma detalhada, o conjunto de alterações que vêm ocorrendo no perfil econômico da região Sul Fluminense, particularmente desde que o município de Volta Redonda mergulhou em uma profunda crise, nos anos 1990. Nessa parte da discussão, recupera-se o percurso trilhado por um grupo de empreendedores institucionais até se chegar à elaboração da estratégia conhecida como Mercado Comum do Vale do Paraíba (Mercovale), que teve como reflexo a tentativa de implantar uma organização política capaz de fomentar a competitividade regional. Caberá, por exemplo, destacar que, nos últimos anos, tem havido uma retomada quase periódica de discussões sobre propostas com esse caráter de integração, sempre passando pela problemática relação entre Volta Redonda e CSN, e que, até agora, todas fracassaram.

\section{EXPERIÊNCIAS DE GOVERNANÇA EM ÁREAS INDUSTRIAIS DEGRADADAS}

Esta discussão sugere como hipótese que a capacidade de recuperação econômica demonstrada por certas regiões de tradição industrial e afetadas por crises provocadas por desaceleração na produção industrial, aumento do desemprego e 
saída de unidades fabris, em grande parte, decorre da verificação, nesses mosaicos, da presença de agentes e instituições sociais que dispõem de recursos políticos acumulados e capazes de compartilhar esforços no sentido de identificar, para a sua região, novas potencialidades econômicas.

São diversas as conjunturas a trabalhar com a ideia de revitalização de antigas áreas industriais com base no desenvolvimento de políticas e programas por meio da articulação de agentes públicos e privados. Em interessante reflexão acerca da degradação urbana e industrial observada em cidades norte-americanas e europeias vitimadas pelo fechamento de plantas siderúrgicas, Deitrick e Beauregard (1995) argumentam que, na segunda metade do século XX, cidades monoindustriais rapidamente se converteram em autênticos cinturões da ferrugem ou rust-belt communities, tendência acompanhada por um forte esvaziamento econômico. No caso específico da tradicional atividade siderúrgica norte-americana, uma forte redução se deu entre os anos de 1970 e 1985, à medida que cidades como Monessen, Braddock e Mckeesport, no Mon Valley, região no sudoeste da Pensilvânia, banhada pelo rio Monongahela, perdiam a base industrial da qual dependiam. O fechamento de plantas siderúrgicas de propriedade da United States Steel Corporation, controladora de $67 \%$ da produção de aço dos Estados Unidos, conjugou-se à decomposição de importantes setores da economia desse estado, especialmente indústrias associadas ao setor têxtil e ao de vestuário, atingindo, depois, a mineração (sendo importante considerar que a Pensilvânia era responsável por $80 \%$ da produção do país). O colapso se deu com a fragmentação da atividade siderúrgica e com a perda, em poucas décadas, de um terço dos seus empregos industriais. ${ }^{1}$

A saída para reverter o cenário de estagnação da região produtora de aço foi apostar

\footnotetext{
${ }^{1}$ Ainda de acordo com Deitrick e Beauregard (1995), em 1986, o panorama da siderurgia na Pensilvânia se tornou definitivamente crônico, porque a United States Steel Corporation anunciou o fechamento da Homestead Works, a mais proeminente de todas as usinas siderúrgicas da região do rio Monongahela, localizada na homônima e histórica cidade.
}

numa estratégia de regeneração da economia regional do estado com base na diversificação e na substituição de um perfil altamente especializado e focado na manufatura por outro, com predomínio de atividades ligadas à administração pública, ao comércio e à prestação de serviços (sobretudo, educação e saúde). Os autores identificam como recorrente, nessa região, ao menos desde a década de 1960, a elaboração de iniciativas de regeneração do tecido urbano e social a partir de iniciativas de governança municipal, como conselhos e experiências de public-private partnership. Em suma, a hipótese é que a retomada de uma trajetória ascendente de desenvolvimento foi possível também porque agentes locais, organizações e municipalidades mostraram-se capazes de atuar de forma concertada em prol da diversificação da economia e da revitalização de áreas vizinhas a usinas siderúrgicas, procurando minimizar passivos ambientais e elaborando ações de modernização da infraestrutura urbana (rodovias regionais, aeroportos etc.) (Deitrick; Beauregard, 1995). Ou seja, a grande estratégia de recuperação parece ter se dado não no sentido de conquistar novos investimentos que reconstruíssem o elo da região com essa atividade industrial, mas na elaboração de um plano de desenvolvimento regional fundado na desvinculação da sua paisagem econômica da imagem da siderurgia.

É possível que certos contextos regionais tenham alcançado êxito na proposta de se repensar em função da forte presença de instituições cívicas alicerçadas e na existência de um histórico de organização, associação, concertação e voluntariedade, conforme salienta Cooke (1995). Portanto, seria o caso de reconhecer, no âmbito das reflexões sobre elaboração e funcionamento de políticas de desenvolvimento regional, a incorporação e valorização de organizações da sociedade civil (Bandeira, 1999), no domínio da governança social e econômica regional, reunidas sob o conceito de "democracia associacional” (Hirst, 2002). A "capacidade de auto-organização da sociedade", espontânea e de baixo para cima, poderia funcionar como um recurso para o desenvolvimento 
(Bagnasco, 2001; Heller, 1996; Locke, 1995; Locke; Jacoby, 1997; Putnam, 1996; Tendler, 1998), destacando-se que, em algumas regiões, a influência de organizações locais na mobilização, no uso de recursos e na maneira como os bens públicos são produzidos pode ser ativa e decisiva. Associações, movimentos políticos e sociais, além de outras redes informais, poderiam, inclusive, substituir o Estado na construção de bases e estratégias para enfrentar as adversidades (Abramovay, 2001). Basicamente, o que uma governança eficiente requer é transparência, fluxo adequado de informações e incorporação de sentimentos de comunidade, margeados pela presença de uma sociedade civil capaz de se autogerir. E, onde esses mecanismos mínimos de democratização foram observados, constatou-se um êxito substancialmente maior na implementação de ações de redução do desemprego, na geração de novas vagas e oportunidades de trabalho, cicatrizando, com maior velocidade e eficiência, as feridas da desindustrialização (Cooke, 1995).

Localidades com alto grau de "sociabilidade cívica" demonstram maior propensão para se tornar "regiões inteligentes" (Cooke, 1995), isto é, regiões com alto grau de confiança entre os agentes do desenvolvimento, mais facilmente adaptáveis a exigências, como o compartilhamento de custos e riscos, a troca informações e a disponibilidade em resolver problemas via colaboração (Pike; Rodriguez-Pose; Tomaney, 2008). A inteligência de uma região se faria sentir mediante o sucesso de mecanismos de interação entre firmas, agências de desenvolvimento, cidades, etc.

Klink (2001) enxerga, na promoção de iniciativas bottom-up, uma grande oportunidade de revitalização e de incorporação de dimensões de cidadania. Considerando que alguma estratégia cooperativa seja adotada, é provável que ela reúna agentes locais que não reconhecem, no comportamento competitivo, necessariamente uma vantagem para a região. Essa é uma constatação comum a reflexões (Arbix, 2000; Bresciani; Klink; Lépore, 2007; Leite, 2003 etc.) ocupadas em descrever articulações reunindo público e privado, e que demonstrem o virtuosismo dos esforços coletivos para se defender do declínio industrial.

Discorrendo a respeito da articulação entre poder público e sociedade civil no ABC paulista, ao longo das últimas duas décadas, outros autores (Ramalho; Rodrigues; Conceição, 2009) compartilham da mesma opinião, argumentando que as experiências dessa região serviram tanto para abrir um debate sobre as situações de crise de distritos industriais tradicionais de base fordista, confrontados com as mudanças trazidas pela reestruturação e flexibilização do processo produtivo, quanto para valorizar a relevância das práticas de articulação política estruturadas em função das necessidades colocadas pelo e no território, sem com isso rejeitar a participação de agentes e representantes de órgãos públicos nessa conjuntura de revitalização local, decisiva para o êxito de programas e estratégias de recuperação e revitalização, como o marketing regional, a internalização de serviços industriais avançados, o processamento de dados, a logística etc.

A preocupação e o interesse acadêmico pelo $A B C$ se justificam pelo choque econômico sofrido por essa região quando, nos anos 1990, o setor automobilístico nacional -carro-chefe do seu desenvolvimento industrial-foi amplamente prejudicado pela reestruturação produtiva genuinamente sistêmica (Cardoso, 2000). A alteração completa na estrutura da cadeia automotiva brasileira a partir da adesão a técnicas japonesas de produção e organização do trabalho, a redefinição da relação entre os diversos elos da cadeia produtiva, o redesenho das plantas industriais, o uso de novas tecnologias e a mudança no padrão dos produtos levaram ao corte de milhares de postos de trabalho em plantas industriais acostumadas a empregar em grande proporção. Essa foi uma situação bem característica, por exemplo, na planta da Volkswagen, em São Bernardo do Campo, a qual, na década de 1970, chegou a empregar até 35 mil trabalhadores (Cardoso, 2000). E, conforme sugere Conceição (1998), esse tipo de proposta industrial-caracterizada pela presença de uma numerosa mão de obra impulsionada pelo ritmo do modelo de produção fordista - foi a mais atingida pelo fechamento de plantas, por demissões em massa e pela redução de investimentos. 
Indiscutivelmente, a crise observada a partir do início dos anos 1990 foi provocada pela conjugação entre a incorporação de técnicas japonesas e a expansão de um processo ainda pouco dimensionado de globalização. Segundo Garcia (2009b), a globalização é um processo não homogêneo e com consequências paradoxais: grande parcela da população localizada e confinada; capital móvel; trabalhador nacionalmente localizado e estático; riqueza e renda não exatamente globais, mas nacional e regionalmente distribuídas entre os Estados. Ela teria criado uma nova realidade econômica e social marcada por novas regras, obrigando atores individuais e coletivos a orientarem suas ações segundo referências competitivas, tecnológicas, políticas e culturais globais. O autor contesta a explicação simplista de que o vendaval da globalização fragmenta as estruturas locais, argumento comum entre a literatura preocupada com os efeitos danosos do processo sobre regiões inteiras, como o próprio ABC. Interpretá-la exigiria considerar respectivamente aspectos de transitoriedade, multiformidade e multidimensionalidade, isto é, interpretá-la como um processo impositivo, marcado pela combinação entre permanência, descontinuidade e mudança, e que está transformando a realidade social; como um processo que provoca efeitos heterogêneos sobre os diferentes atores sociais, criando riscos e oportunidades variados para os diversos atores que constituem a esfera local; mas que, ao mesmo tempo, tem, nas diferentes dimensões da realidade social, suas condicionantes.

Particularmente, a multidimensionalidade argumenta que referências globais (padrões competitivos etc.) demandam ajustes dos agentes sociais (empresas, empresários, sindicatos, governos etc.). Esses, por sua vez, dependem da conjugação de certos fatores, como conjuntura política, instituições locais, recursos econômicos, políticos e sociais etc. A globalização não seria tão somente um processo orientado pelas forças incontroláveis do mercado, mas igualmente condicionada pelas estratégias dos atores locais. Aqui, o caráter dialético e conflitivo das relações entre agente globais e locais é realçado, e a assimetria de poder entre essas duas esferas passa a equivaler à elaboração de es- tratégias de resistência, bem como à possibilidade de existência de "margens de manobra" para os atores locais (Garcia, 2009b, p. 41).

A percepção que se tem é que a problemática da reestruturação produtiva e da integração competitiva de empresas e outros atores econômicos em contextos globalizados, em paralelo à defesa de uma economia mais integrada e flexível, talvez tenha contribuído também para introduzir outro debate acerca da constituição de novas instituições e espaços públicos em nível subnacional (Guimarães; Martin, 2001, p. 16). Sobretudo, distritos industriais e polos de desenvolvimento em declínio constituir-se-iam em cenários privilegiados para experiências de canais de governança em âmbito regional, mediante uma "proposta de desenvolvimento mais localmente imbricado e embebido nas iniciativas de coordenação dos atores locais." Trata-se de uma resposta, segundo os autores, à economia globalizada, que sucedeu a antiga variedade de capitalismo fundada em um modelo de gestão genuinamente paternalista, marcado pela presença de um Estado regulador, nacionalista e intervencionista, e por um perfil de trabalhador assalariado com vínculo formal de emprego. De forma quase natural, a desverticalização promovida pelo enfraquecimento do Estado-nação regulador aprimorou um modelo de governança alicerçado no fortalecimento da escala subnacional e também no aperfeiçoamento de coletividades territoriais compostas por um grande número de associações e movimentos. Essas mobilizações passaram a constituir redes políticas de coordenação horizontal, constituindo-se em alternativas frente à redução do ímpeto de organizações e ações coletivas mais emblemáticas, como os sindicatos (Bourdin, 2001). Nesse sentido, a possibilidade de elaboração de estratégias de resistência e redesenho institucional, a despeito da evidente assimetria de poder entre a diversidade de atores e interesses envolvidos, bem como do custo político que isso possa acarretar, estaria contida no debate acerca da dinâmica da regionalização que se estabelece a partir da relação global versus local.

Se, por um lado, o discurso oficialmente 
vigente sinaliza para os efeitos drásticos sobre a economia e o nível de emprego de muitas regiões de tradição industrial e a subordinação econômica de populações aos interesses e à impossibilidade de governabilidade das forças de mercado, passando as práticas sociais (locais) a ser justificadas e orientadas pelo avanço da globalização, por outro, vale pensar a respeito da capacidade de regeneração dessas trajetórias de dependência. Assim, uma primeira constatação a ser assinalada é acerca da ineficiência de estratégias universais que desconsiderem os contextos locais. Segundo Pike, Rodriguez-Pose e Tomaney (2006), estratégias ou políticas top-down têm tido pouco resultado no sentido de garantir um desenvolvimento prolongado dessas localidades, porque alienam a população afetada de discutir e construir o futuro do seu território. Assim sendo, quatro aspectos constituiriam uma estratégia consistente de desenvolvimento regional: participação e diálogo, territorialidade, mobilização dos recursos locais e das vantagens competitivas, além da propriedade e administração local desse processo (White; Gasser, 2001 apud PIKE; Rodriguez-Pose; Tomaney, 2006).

Procurando recusar certas explicações simplistas sobre a derrota de regiões inteiras para as forças globais, ${ }^{2}$ seria o caso de se enxergar além dos efeitos negativos que a globalização pode expressar sobre localidades - usando-as para a obtenção de vantagens (baixos salários, isenção de impostos, novas formas de controle etc.) - e de perguntar se e como surgem "chances de prosperidade econômica, ampliação de capacidades e qualificações, mudanças na cultura organizacional e sindical, expansão da densidade institucional e política” (Garcia, 2009b, p. 42), além de outros efeitos positivos para essas regiões atingidas.

À estrutura de oportunidades políticas e econômicas (criadas em conjunto com a globalização) somam-se as redes, relações e recur-

${ }^{2} \mathrm{O}$ exemplo mais concreto da via de mão dupla em que se constituiu a globalização é a mudança de paradigma de trabalhadores industriais e de seus sindicatos. Ao passo que abandonam greves e amenizam o tom de conflito, incorporam novos interesses e valores, além de identificarem e se apropriarem de novas oportunidades econômicas e políticas nas suas regiões (Garcia, 2009a). sos sociopolíticos responsáveis pela configuração de arranjos subnacionais e pelo padrão de associativismo de um território. Nos mais diversos contextos industriais, os tipos variados de redes e arranjos funcionam como estruturas ou modelos de interação que interferem na "habilidade dos atores em diferentes localidades em compartilhar informações, recursos e formar alianças em momentos críticos.” (Locke, 1995, p. 125). ${ }^{3}$ Em alguns contextos, grupos, organizações e até partidos políticos puderam se tornar suficientemente fortes e bem organizados a ponto de serem responsáveis, durante o processo de reestruturação vivido por empresas, por organizar

[...]seminários e conferências para aproximar sindicalistas, gerentes, políticos e acadêmicos para discutirem questões associadas às transformações em curso na indústria, estimulando a divisão de informação e desenvolvendo o diálogo entre diferentes grupos (Locke, 1995, p. 132). ${ }^{4}$

Conforme afirma Scott (2004), a economia sofre efeitos histórico-institucionais, e processos de empreendedorismo, inovação e aprendizado que ocorrem no espaço físico e econômico não podem

A reflexão de Locke (1995) incide sobre as variações no perfil da economia italiana, distinta regionalmente segundo padrões estabelecidos de associativismo, representação política e governança econômica. Cada localidade preserva formas específicas de relacionamento entre grandes empresas e grupos sociais componentes do seu tecido social. Para interpretar essas disparidades, o autor elabora três tipos ideais de arranjo sociopolítico. O primeiro entende que, em certas regiões, associações, primeiro entende que, em certas regioes, associaçoes,
movimentos políticos, sociais e empresariais ficam divididos em dois campos fechados, com ligações muito fracas entre si, ao passo que se mantêm fortemente vinculados e dependentes dos policymakers centrais (modelo polarizado); em outro, onde os grupos de interesse são mais numerosos, há o predomínio de relações estritamente fragmentadas e hierarquizadas entre os atores sociais (modelo hierárquico); por fim, apresenta-se um sistema basicamente caracterizado pela existência de uma densa rede de associações e grupos de interesses ligados por laços horizontais (modelo policêntrico).

${ }^{4}$ Em outro exemplo acerca do poder de interferência de uma rede sociopolítica composta por uma vibrante sociedade civil nos rumos do desenvolvimento econômico de uma cidade ou região, Locke e Jakoby (1997) descrevem o funcionamento do vocational training system um sistema de educação técnica oferecido por institutos tecnológicos para qualificar trabalhadores como operadores em indústrias com alta demanda por pessoal capacitado, como a automobilística, cujo funcionamento adequado exige a presença de um setor privado dinâmico e de uma bem articulada rede de organizações e associações, sobretudo câmaras de comércio e sindicatos em Leipzig e Chemnitz, cidades alemãs de grande população operária e vinculadas a atividades de produção au- 
omitir a relevância dos nexos culturais, políticos e sociais no sentido de ajudar a modelar as dinâmicas locacionais. Dessa forma, é preciso reservar um espaço analítico e descritivo para a ação coletiva e a ordem institucional nos mais variados níveis organizacionais e espaciais (firma, mercado de trabalho local, região, nação etc.) e ajudar a responder a questão sobre como se constroem arranjos institucionais locais que promovam tanto o sucesso econômico quanto a justiça social. Esse parece ser o caminho adotado pela geógrafa Ann Markusen (2005, p. 71), ao discursar sobre o fortalecimento e a autonomização de regiões e defender análises "com mais nuances institucionais e mais centradas no ator" contra o "excessivo gasto de energia acadêmica em conceitualização e em narrativas causais que substituem atores por processos" (Markusen, 2005, p. 58). Nesse sentido, em vez de "os atores estarem dando forma à geografia econômica, estar-seia atribuindo papéis causais a fenômenos subteorizados, tais como aprendizagem e rede". A autora reconhece o potencial das organizações de âmbito regional, incluindo grupos de interesse trabalhadores, empresários, grupos comunitários e ambientais - que desempenham importante papel no cumprimento da agenda de organização regional. Embora o seu enfoque recaia especialmente sobre empresas, na qualidade de principais unidades de decisões privadas, e sindicatos trabalhistas, na qualidade de agentes representantes dos trabalhadores, Markusen (2005) reconhece que atores igualmente importantes - entidades de caráter não lucrativo, cooperativas, grupos comunitários, associações profissionais, organizações religiosas,

tomobilística, têxtil, química e de equipamentos. Essas cidades sofreram com a desindustrialização, depois de 1989, enfrentando também uma drástica redução do emprego industrial. Após a reunificação da Alemanha, as duas sucumbiram diante do fechamento de plantas industriais, de uma redução significativa do trabalho metalúrgico, do subemprego e da migração em massa de trabalhadores em fuga da crise. Porém, apesar de experimentarem semelhantes políticas de transferência institucional do governo nacional a fim de recuperar áreas industriais degradadas, as duas cidades responderam de forma diferente aos projetos institucionais de requalificação da mão de obra e de sua reinserção no mercado de trabalho, bastando dizer que Leipzig apresentou resultados mais satisfatórios por conta da maior cooperação e coordenação entre associações, grupos e firmas locais, bem articulados por uma reabsorção dessa força de trabalho. indivíduos e, acima de tudo, o Estado - deveriam ser explorados como agentes cujos comportamentos e tomadas de decisão são relevantes, a ponto de conseguirem alterar as economias regionais. A despeito da repercussão negativa das decisões tomadas pelas corporações no seio de trabalhadores e comunidades, Markusen (2005) identifica, nesses agentes, a capacidade de empreender estratégias, como pressionar por legislações que retardem ou regulem o fechamento de plantas, apoiar programas de deslocamento de mão de obra, ou convencer empregadores a serem parceiros dos empregados com o intuito de aperfeiçoar programas de qualificação profissional e de estabilização do emprego regional.

\section{NASCIMENTO E REFLUXO DAS ESTRATÉGI- AS DE CONCERTAÇÃO NO SUL FLUMINENSE}

Discutir o processo de regeneração de territórios e distritos industriais na conjuntura do Sul Fluminense tem-se confirmado tarefa complexa, uma vez que os principais municípios da região vêm atravessando momentos distintos no que se refere a taxas de expansão econômica. Em uma direção, segue o conjunto de municípios notabilizados por concentrarem investimentos, sobretudo da indústria automobilística, tendência fortemente confirmada a partir da década de 1990. Resende, Porto Real e Itatiaia são municípios em franca expansão econômica e populacional, confirmada por investimentos recentes realizados por grandes companhias. A Votorantim inaugurou uma usina siderúrgica, em Resende, em outubro de 2009; a Michelin vem concluindo a expansão da sua fábrica de pneus, em Itatiaia; enquanto MAN (fabricante de ônibus e caminhões Volkswagen) e PSA Peugeot-Citröen anunciaram planos de expansão para suas unidades, em Resende e Porto Real, respectivamente. Somando-se a isso, duas montadoras (a japonesa Nissan Motor Company e a coreana Hyundai Heavy Industries) oficializaram a construção de fábricas em Resende, fortalecendo a vocação industrial e, mais especificamente, automobilística desse município. 
Segundo a Firjan, ${ }^{5}$ os três municípios receberão $\mathrm{R} \$ 4,1$ bilhões em investimentos entre $2012 \mathrm{e}$ 2014 , o equivalente a $30 \%$ dos $\mathrm{R} \$ 14,2$ bilhões destinados ao Sul Fluminense no período. [...] A reboque do boom automotivo, a região passa por uma intensa transformação. As prefeituras locais têm negociado mais $\mathrm{R} \$ 600$ milhões em novos projetos de segmentos como têxtil, cosméticos, siderurgia e logística, o que, somado aos R $\$$ 4,1 bilhões, chega a R $\$ 4,7$ bilhões. [...] O incremento da indústria e do comércio tem se traduzido no aumento de salários e geração de empregos na região. [...] À exceção de 2009, auge da crise global, os salários pagos em Resende, Itatiaia e Porto Real cresceram acima da média no período. (Durão, 2011, nota nossa).

Porém, ao passo que algumas unidades administrativas da região vêm se expandindo rapidamente, outras enfrentam dificuldades, caso de Volta Redonda. Ainda na condição de município mais rico de toda a região, com um PIB de quase R\$ 8,4 bilhões, ${ }^{6}$ em 2009, Volta Redonda, desde a privatização da CSN, vem assistindo a mudanças significativas no seu perfil econômico a partir do crescimento de atividades de serviços ligadas a educação, saúde e administração pública. São alterações com impacto direto na manutenção de sua identidade, outrora predominantemente industrial e operária, acompanhadas também da crescente saída de mão de obra treinada e qualificada pela Companhia. Esse contingente de trabalhadores vem trocando, cada vez mais, condições de trabalho precárias, com baixa remuneração, por ocupações em novos empreendimentos siderúrgicos fora e dentro do estado, como a Companhia Siderúrgica do Atlântico (CSA), em funcionamento na capital fluminense, e a Votorantim Siderurgia, em Resende.

Contudo, a preocupação com o declínio é anterior, remetendo a meados da década de 1990, e está na essência do engajamento das autoridades políticas de Volta Redonda, apoiadas por Barra Mansa, a favor da união de esforços em prol de

${ }^{5}$ Federação das Indústrias do Estado do Rio de Janeiro.

${ }^{6}$ O Produto Interno Bruto de Volta Redonda variou, entre 2005 e 2009, de $\mathrm{R} \$ 5.714 .374$ bilhões a $\mathrm{R} \$ 8.394 .797$ bilhões. No mesmo período, o PIB de Resende saltou de R\$ 2.870.472 bilhões para R\$ 5.011 .075 bilhões e o de Porto Real subiu de R\$1.814.553 bilhões para R\$ 3.502.627 bilhões. Esses dois municípios, percentualmente, tiveram um crescimento mais significativo no período (IBGE, 2011). um programa de desenvolvimento mais integrado para o Sul Fluminense. Dessa fase provêm os mais elaborados esforços de construção de um projeto de governança regional, envolvendo agentes como o Sindicato dos Metalúrgicos do Sul Fluminense, o Sindicato das Indústrias Metalúrgicas, Mecânicas, Automotivas, de Informática, e de Material EletroEletrônico do Médio Paraíba e Sul Fluminense (MetalSul) e as próprias Prefeituras.

Eu prefiro acreditar em um projeto de consórcio regional. Volta Redonda é exportadora de mão de obra. Quando você pensa na vinda de uma empresa, você tem duas coisas importantes. Uma é que ela vai trazer receitas para o município e outra que ela vai consumir produtos da cidade ou da região. Entendemos que o nosso desenvolvimento precisa ser olhado de maneira um pouco mais ampla (Volta Redonda, 2010).

Volta Redonda se transformou no principal interlocutor dessa proposta, à medida que a privatização foi gerando forte expectativa de crise e fechamento de empresas. ${ }^{7}$ Em 1996, a Associação Sul Fluminense das Indústrias Metal-Mecânicas (Asimec), uma entidade integrada por cerca de trinta empresas prestadoras de serviços para a siderúrgica, testemunhou a fragmentação do incipiente cinturão de fornecedores existente na região, formado por cem pequenas e médias empresas fornecedoras de peças à $\mathrm{CSN}$ e a fundições e metalúrgicas locais dedicadas à manutenção de equipamentos da Companhia. Há tempos, os segmentos empresariais locais planejavam canalizar o aporte institucional da Companhia para a construção de um novo distrito industrial. ${ }^{8}$ Entretan-

${ }^{7}$ Maiores detalhes sobre a complexidade da privatização da CSN para a população de Volta Redonda são encontrados em Pereira (2007) e Lima (2010).

${ }^{8} \mathrm{O}$ primeiro plano de um distrito industrial data de 1971 , em área dentro da fazenda Três Poços, no limite entre Volta Redonda e Piraí. A segunda tentativa é de 1979, quando os prefeitos de Volta Redonda, Barra do Piraí e Piraí assinaram uma carta de intenções e realizaram uma reunião com o presidente da Companhia de Desenvolvimento Industrial (CODIN) e com cerca de 70 empresários interessados em instalar suas indústrias no distrito industrial, fornecendo produtos acabados à Companhia Siderúrgica Nacional (Jornal do Brasil, 1979). Já em 1983 empresários de Volta Redonda voltaram a discutir a implantação do distrito, dessa vez com 311 mil metros quadrados e com capacidade para comportar 30 empresas de médio porte (A Crise ...,1983). Nenhum dos projetos alcançou êxito. 
to, alegando buscar mais qualidade com preços menores, a CSN optou por substituir esses fornecedores por empresas de outros estados, reduzindo suas compras anuais na região, o que levou o cinturão a perder em torno de $70 \%$ dos seus negócios e a demitir aproximadamente 1,5 mil dos seus 3 mil trabalhadores (Dias; Simões; Schüffner, 1998). O fracasso do cinturão de fornecedores provocou o fechamento de diversas empresas da região por falta de capital para investimento, ao passo que outras sobreviveram ao cortar gastos e reduzir o número de empregados. Esse preocupante cenário de demissões complementava o downsizing iniciado na Companhia no final da década de 1980, e que previa um enxugamento radical no seu quadro de funcionários a fim de se adaptar a um padrão mundial de empregos.

Em agosto de 1997, o Diário do Vale, (Crise..., 1997) um dos principais jornais da região, relatava a redução no número de empregos e o seu efeito sobre o comércio, obrigando a Associação Comercial, Industrial e Agropastoril de Volta Redonda (ACIAP-VR) a defender uma ação integrada e a troca de informações entre os diversos setores sociais. Esse foi o estopim para que um projeto conjunto entre vários municípios da região, sob a forma de uma economia regionalizada, passasse a ser defendido por lideranças, inclusive do Sindicato dos Metalúrgicos, como mecanismo de atração de novas empresas e criação de cooperativas que empregassem funcionários demitidos pela privatização.

No ano de 1997, a proposta de um projeto coletivo em âmbito regional começou a ganhar proporção com a realização de um "Fórum de Secretários de Planejamento" constituído com o propósito de trocar informações e experiências municipais que facilitassem a criação de uma nova instância articulatória (Amaral, 2001) para tratar do meio ambiente, da questão da mão de obra e da falência de indústrias nesses municípios fluminenses. Sinalizando para o preocupante balanço de cinco mil empregos cortados na CSN apenas entre 1993 e 1997, o fórum aglutinou a comum preocupação dos secretários com os rumos da economia nacional e com os efeitos da globalização sobre a indústria brasileira, encarregando-se de preparar um relatório de atividades, depois apresentado aos integrantes de movimentos sociais da região. Entre seus principais empreendedores institucionais, estavam os secretários de planejamento dos municípios de Volta Redonda e Barra Mansa. E deve-se ressaltar que o projeto foi favorecido, em grande medida, pela conjuntura política da região, uma vez que, no ano de 1997, cinco das doze Prefeituras eram administradas pelo Partido Socialista Brasileira (PSB) e pelo Partido dos Trabalhadores (PT), partidos que preservavam a afinidade ideológica necessária para o sucesso de uma proposta de concertação envolvendo municipalidades.

O fórum resultou na "Caravana I", uma série de encontros ocorridos entre os meses de fevereiro e março de 1997, envolvendo prefeitos eleitos, vereadores e secretários em cada uma das localidades, concretizando a adesão de oito desses municípios a uma proposta de administração articulada. A partir disso, foi elaborada a iniciativa denominada por Mercado Comum do Vale do Paraíba (Mercovale), uma marca do desenvolvimento integrado da região, almejando construir um planejamento estratégico capaz de descobrir e fomentar a potencialidades dos municípios da região, os quais viriam a compor a nova organização política regional. Sua pedra fundamental foi lançada em maio do mesmo ano, com um estudo que ficou a cargo de duas consultorias, a KPMG e a Agência 21, tendo, entre os seus consultores, César Maia, ex-prefeito do Rio de Janeiro (Leitão, 1997). O plano assumia como premissas a dependência de recursos acima dos disponíveis localmente a fim de se promover o desenvolvimento socioeconômico; 0 reconhecimento de que a procura por esses recursos exigiria uma postura proativa para a sua atração; o planejamento, a avaliação de prioridades e a articulação entre agentes públicos e privados para a atração e multiplicação de investimentos nesse ambiente competitivo; e a articulação entre municípios com vocações e ofertas complementares como forma de caracterizar uma vantagem competitiva fundamental (Relatório , 1997). 
Era um conjunto de secretários de planejamento da região, que se reuniu por mais de um ano com regularidade, todos os meses, para discutir a política regional. Eu era secretário de planejamento de Barra Mansa. O nome Mercovale quem deu foi Barra Mansa. O meu prefeito, quando eu mostrei a ideia, perguntou: seria uma espécie de Mercovale? Era isso que a gente precisava. E fui para reunião de secretários com o nome embaixo do braço. E todo mundo aprovou. Nós tínhamos uma consultoria do Rio de Janeiro, que acompanhou o processo de construção desse pensamento de planejamento e desenvolvimento regional. Quando veio a ideia, a gente imediatamente pensou na criação de uma agência de desenvolvimento regional. A agência seria um tripé entre governo, sociedade organizada e iniciativa privada. Esta agência teria um caráter privado e inspirado no modelo do $\mathrm{ABC}$, que nós fomos conhecer e trouxemos. Ex-secretário de planejamento de Barra Mansa, Volta Redonda, 15/05/08.

O pressuposto era sedimentar as bases de um ousado processo de integração regional (Santos, 2006), que previa a atração de investimentos industriais e a elaboração, no plano econômico e político-institucional, de novas estratégias de desenvolvimento, sendo uma delas a criação de uma agência que atuaria ao lado de um planejamento estratégico e do conselho do Mercovale (formado por representantes do poder público, da iniciativa privada e da sociedade civil) como instrumento de valorização e fortalecimento da sinergia entre os municípios do Sul Fluminense. Esperava-se, assim, motivar o estabelecimento de relações de parceria entre agentes estatais e grupos societais locais, sobretudo empresários e trabalhadores.

Os representantes dos governos municipais, de entidades representativas de classe, clubes de serviço e lideranças comunitárias dos municípios assinaram uma carta de intenções, com o intuito de formar um Conselho de Desenvolvimento Regional que buscasse soluções e direcionasse os processos de investimento na região. O conselho apresentaria propostas de trabalho e definiria a estratégia de atuação da agência. E, pela proposta, haveria um estímulo à participação de representantes das cidades no processo de regionalização e integração dos municípios. Porém, pouco depois, a agência acabou estagnando e os grandes atores sociais da região, em especial a CSN, demonstra- ram pouco interesse pelo projeto do Mercovale. A isso se soma a heterogeneidade dos municípios, incluindo alguns com curta existência, como Porto Real (emancipado em 1995, sem histórico de mobilização política e de presença de lideranças e representações políticas, sindicais e empresariais organizadas), outros com um perfil industrial consolidado e um importante legado de organização popular-sindical, caso de Volta Redonda.

Conforme descreveu o ex-secretário de planejamento de Barra Mansa, o Mercovale foi inspirado no modelo implantado no $\mathrm{ABC}$, e seus articuladores atribuem à mudança na presidência da CSN e às transições nos governos municipais o fracasso de uma ideia fortalecida pelo sentimento regional prevalecente no período. Além desses fatores, o seu uso político por lideranças e a incapacidade de os municípios integrantes elaborarem o planejamento estratégico regional, elemento-chave para a implantação e êxito, teriam contribuído para o fracasso do empreendimento coletivo. O seu refluxo não foi acompanhado, contudo, pela redução de um discurso pró-integração regional que, ao contrário, se fortaleceu entre alguns dos principais agentes políticos, os quais entendiam haver a necessidade de se adotar uma concepção regional que articulasse um posicionamento estratégico diante dos desafios colocados pela mundialização da economia. Nesse sentido, alguns secretários de planejamento afirmavam que as lideranças locais precisavam abrir um espaço de planejamento, além dos seus interesses imediatos, sob a diretriz de um movimento político de afirmação do Sul Fluminense e de constituição de um fórum que superasse diferenças nas agendas do governo e das principais empresas da região (Cunha, 2001).

Antes de tudo, o Mercovale tornava-se essencial mediante a incapacidade de a atividade siderúrgica da CSN continuar criando externalidades positivas na mesma proporção que as autoridades de Volta Redonda desejavam e em gerar uma dinâmica capaz de atrair novas atividades e, consequentemente, um novo mercado a jusante dessa atividade (Cunha, 2001). Com uma infraestrutura programada para atender exclusivamente às exigências de expansão 
da atividade siderúrgica, os municípios ${ }^{9}$ liderados por Volta Redonda viam-se incapazes de atrair atividades industriais capazes de agregar valor ao produto siderúrgico, tendência ligeiramente estancada pelo empenho dedicado à construção de um polo metal-mecânico, sobretudo por iniciativa do MetalSul, entidade mais interessada na formação de um arranjo produtivo local do setor na região.

Oreconhecimento dessa proeminência leva a concluir que a CSN, integrada desde sua origem ao esforço de configuração de um novo padrão de acumulação no país, em parte representou um obstáculo ao êxito do Mercovale, especialmente ao se considerar a relação que construiu com o conjunto dos atores sociais do território do Sul Fluminense (incluindo comunidades, poder público e outros agentes de ordem econômica) (Morel, 1989; Piquet, 1998). A Companhia praticamente modelou uma estrutura sociopolítica na região (mais especificamente em Volta Redonda), encerrando limitações estruturais que dificultaram ou retardaram a construção de parcerias e coalizões, ora no meio sindical, ${ }^{10}$ ora entre associações e grupos empresariais locais. Talvez, nesse sentido, as inferências de Markusen (2005) referentes ao reconhecimento do comportamento dos atores políticos locais como relevantes para um entendimento adequado do que é, de fato, um processo de desenvolvimento regional, bem como sua insistência em aceitar o papel reivindicativo, regulatório e contestatório desses atores frente às corporações, demandem maiores reflexões, quando associadas à conjuntura do Sul Fluminense.

Por fim, a dispersão do movimento próintegração, objetivado na ideia do Mercovale, e a incapacidade de expansão do mercado de trabalho com base na atividade industrial levaram as

\footnotetext{
${ }^{9} \mathrm{O}$ centro comercial de Volta Redonda é muito frequentado por moradores dos municípios vizinhos, especialmente de Barra Mansa e Pinheiral. Esses dois municípios abrigam contingentes expressivos de funcionários da CSN e também foram atingidos pelas demissões da década de 1990. São, portanto, extensões importantes da estrutura socioeconômica fundada a partir do enraizamento geográfico da Companhia.

${ }^{10}$ Análises como as construídas por Mangabeira (1993) e Monteiro (1995) ajudam a revelar o tardio amadurecimento do movimento sindical de Volta Redonda.
}

autoridades políticas e empresariais a identificar, no setor de serviços de Volta Redonda, o dinamismo perdido pela indústria. Como reflexo desse reconhecimento, o poder público municipal, através de sua secretaria de desenvolvimento econômico e turismo (curiosamente constituída apenas em 2006), tem se destacado como importante emulador dessa nova dinâmica, a despeito de paralelamente investir em projetos públicos de fomento a distritos industriais voltados a pequenas e médias empresas. ${ }^{11}$

É importante ressaltar, como argumentam Ramalho e Santana (2001), que o discurso pregando a união entre os municípios, na década de 1990, havia substituído tradicionais práticas retaliatórias e particularistas entre eles, muito em função, talvez, "do contexto de mudanças na economia mundial e de globalização das atividades produtivas”, que fazia da concepção regional uma possível vantagem competitiva no cenário econômico da transição do século XX para o XXI. A globalização e a abertura de mercados teriam deixado as complexas e detalhadas estruturas de regulação e os seus planos diretores desacreditados, tornando o planejamento estratégico um instrumento de redesenho urbano e de aceleração da proposta de revitalização e reconstrução econômica constitutiva da inversão da estratégia discursiva a favor da ideia de governance (Klink, 2001).

Ajudando a compor o conjunto de análises produzidas sobre a transformação em regiões industriais brasileiras desde a década de 1990, Ramalho (2005, p. 14) defende uma análise que reconheça os "elementos estratégicos das ações dos atores sociais locais", incorporando a dimensão política à discussão sobre desenvolvimento e "percebendo como vínculos extraeconômicos podem ser criados onde eles não foram desenvolvidos historicamente" (Roese, 2003 apud Ramalho, 2005, p. 14). O autor destaca a crescente pressão não só sobre as (novas e antigas) empresas da região, como também sobre as municipalidades, no sentido de

${ }^{11}$ A secretaria vem fomentando a construção dos parques
empresariais Roma, Contorno e João Pessoa Fagundes empresariais Roma, Contorn
em Volta Redonda (2013). 
reivindicar maior participação nas decisões referentes a políticas sociais e ao desenvolvimento econômico. Os sindicatos, por exemplo, passam a se envolver com essas questões, indicando uma maior preocupação da instituição com essa problemática. Outros exemplos são a comissão municipal de emprego, a atração de investimentos e a ação regional coordenada. Segundo o autor, a crescente participação de sindicatos e movimentos sociais decididos a estabelecer novos parâmetros que aprofundem as práticas democráticas pode confirmar que "um estoque de práticas organizacionais e a constituição de redes sociopolíticas" vêm, já há algum tempo, ajudando a reorientar politicamente a região e influenciando na criação de fóruns e conselhos municipais (Ramalho, 2005).

A proposta do Mercovale foi praticamente estancada em 2001, talvez por falta de uma verdadeira articulação supramunicipal ${ }^{12}$ dos agentes mais emblemáticos do desenvolvimento e pela incapacidade de eles enxergarem a necessidade de enraizamento desse protótipo de nova institucionalidade em um ambiente de confiança necessariamente caracterizado por uma cultura inovadora de planejamento regional (Bresciani; Klink; Lépore, 2006). Não obstante, o esforço para sua estruturação revela o sentimento de que as heranças negativas da privatização, em algum momento, precisaram ser remediadas pela (re) aproximação entre os vários segmentos e setores sociais, objetivando compor uma união de forças capaz de superar coletivamente os problemas identificados na região. Também teve o mérito -

${ }^{12}$ A facilidade de transformar em prática a retórica do discurso mais integrado e regional é facilmente desconstruída por eventos como a disputa para acolher a GalvaSud (atual CSN Porto Real), unidade voltada para a fabricação de aços galvanizados para o mercado automobilístico. No final da década de 1990, a CSN e o grupo alemão ThyssenKrupp anunciaram a formação de uma joint venture para a instalação da fábrica e oficializaram a escolha por Porto Real. Porém, a Prefeitura de Volta Redonda, que havia se comprometido a cobrir ofertas de incentivos fiscais feitas por outras Prefeituras do país, julgou a opção pelo município vizinho como uma decisão de caráter mais político do que técnico do Conselho de Administração da Companhia. "Estou muito decepcionado. Lamento profundamente a ida da GalvaSud para Porto Real. Não que eu tenha algo contra a administração e a população daquela cidade. Torço pelo meu país, pelo meu estado e pela minha região, mas sempre estarei disposto a brigar muito pela minha cidade" - afirmou o prefeito Antonio Francisco Neto (Diário do Vale, 1998). especialmente em um contexto de atuação do movimento popular-sindical associado à existência de um contingente operário cada vez mais expressivo (a partir das plantas automobilísticas implantadas em Resende e Porto Real) (Ramalho; Santana, 2001) - de revelar o compromisso de entidades empresariais e produtivas, como as ACIAPs, o SEBRAE regional e o MetalSul, no sentido de constituir uma esfera de governança que buscasse alternativas de cooperação entre novos e antigos agentes do desenvolvimento econômico e social (Ramalho, 2005).

Contudo, o esforço seguinte em direção a um desenho concertacional só se daria a partir da realização, em fevereiro de 2008, de um Ciclo de Eventos sobre Desenvolvimento, reunindo representantes da Caixa Econômica Federal (CEF), ocasião em que foi lançado (de forma mais vertical) o projeto de uma Agência de Desenvolvimento do Médio Paraíba (ADEMP), alicerçado em uma suposta aliança entre Ministério da Integração Nacional, Polo Universitário da Universidade Federal Fluminense (PUVR-UFF), em Volta Redonda, e demais setores organizados, numa tentativa de formular um espaço de convergência dos atores produtivos regionais. A agência acabaria criada pela ACIAP-VR como uma instância privada alinhada a atores de grande porte, como CSN e Votorantim Metais.

Resolvemos criar a agência, partindo do privado para o público. Essa agência nasce forte porque as empresas estão participando. Ela se propõe a identificar a vocação de cada cidade. Ela terá um conselho de 15 membros. E vamos querer que estejam participando desse conselho as Prefeituras, as entidades, como o SEBRAE, FIRJAN, as entidades de representação do setor produtivo, como o MetalSul, as associações comerciais etc. Esses segmentos são agentes facilitadores para que o projeto possa andar. Superintendente executivo da Agência de Desenvolvimento do Médio Paraíba (ADEMP), Volta Redonda, 23/05/2009.

Em abril do mesmo ano, autoridades municipais, estaduais e federais lançaram a Carta do Sul Fluminense, espécie de declaração oficial conjunta entre governos, que se comprometiam a trabalhar pela constituição, em médio prazo, de uma 
agência regional. A carta foi assinada pelo então ministro da Integração Nacional, Geddel Vieira Lima, pelo governador do estado do Rio de Janeiro, Sérgio Cabral Filho, pelo vice-governador, Luiz Fernando de Souza Pezão, e por prefeitos de catorze municípios da região. As lideranças políticas municipais, estaduais e federais se comprometiam a criar uma Unidade de Apoio ao Desenvolvimento do Sul Fluminense, dedicada a negociar e conduzir, entre outras propostas:

1. a definição de estratégias de desenvolvimento regional que transcendam a lógica dos investimentos setorizados e localizados, criando-se uma ambiência onde o desenvolvimento territorial se apoie na historicidade das sub-regiões, no espaço socialmente produzido e nas experiências acumuladas;

2. a instauração de um processo de planejamento regional para a elaboração de um Plano Estratégico, de médio e longo prazo, e de Planos de Ação específicos, conforme as diretrizes e proposições decorrentes do Ciclo de Eventos sobre o Desenvolvimento do Sul Fluminense, anexas à Carta;

3. a instalação de um fórum que favoreça e legitime as resoluções decorrentes dos entendimentos entre a iniciativa privada, a sociedade civil organizada e os poderes públicos, ao longo do processo de implementação de um projeto de desenvolvimento para o Sul Fluminense;

4. a mobilização de órgãos técnicos, instituições de fomento, institutos de pesquisa e instituições de ensino superior que possam contribuir para a consecução dos propósitos dessa iniciativa;

5. e a implementação de um modelo de gestão do território, apoiado na articulação institucional das três esferas de governo e delas com o setor privado e a sociedade civil, de modo a facilitar a conciliação de interesses, a implementação e o acompanhamento de ações conjuntas voltadas ao desenvolvimento regional (BRASIL, 2008).

O lançamento oficial dessas propostas coincidiu com a explosão de uma nova crise na região, quando a $\mathrm{CSN}$ - após propor um acordo (turno de revezamento de oito horas; a criação de um banco de horas extras; a redução dos benefícios dos empregados e uma licença remunerada com redução salarial, como medidas para evitar a demissão dos funcionários) prontamente rejeitado pelo Sindicato dos Metalúrgicos - demitiu 1.200 funcionários da sua usina em Volta Redonda.

O temor de que as demissões causassem um novo impacto nos setores de comércio e serviço, tal como acontecera dez anos antes, acabou originando uma nova mobilização, o "Fórum Demissão Zero", aglutinando comerciantes e lideranças políticas, representantes da ACIAP-VR, do MetalSul, da Câmara dos Dirigentes Logistas (CDLVR), do Sindicato dos Metalúrgicos, do Serviço Brasileiro de Apoio às Micro e Pequena Empresas (SEBRAE) e do Sindicato dos Engenheiros, além de secretários e prefeitos de seis cidades (Volta Redonda; Barra Mansa; Itatiaia; Pinheiral; Resende e Piraí) para discutirem medidas de enfrentamento da crise e impedir outro ciclo de demissões em massa. Os encontros serviram para discutir saídas que passavam pela readmissão dos trabalhadores, além de alternativas para a cidade e a região, terminando por ampliar o seu escopo com a incorporação do debate ambiental. Os envolvidos discutiram: um pacto de "não demissões"; a ampliação do prazo para o pagamento do IPTU pelas empresas da região; a adoção de $30 \%$ de desconto no IPTU; uma lei geral da pequena empresa; a facilitação das linhas de crédito; além da criação do "compra Sul Fluminense" e do "compra Rio" como mecanismos de estímulo ao comércio.

Por fim, foi assinada uma nova carta compromisso, como esforço final para amenizar a crise nos municípios e solicitar benefícios para empresas locais a fim de conter as demissões e manter os postos de trabalho na região (Turno..., 2009). Em seguida, outros sete encontros foram realizados para discutir novas medidas, a fim de amenizar o impacto da crise econômica na região: a abertura de linhas de crédito para as prefeituras para habitação e compra de equipamentos; a aceleração das obras do Programa de Aceleração do Crescimento (PAC); o encontro de uma comitiva com o vicegovernador Luiz Fernando Pezão, em busca de 
apoio para o movimento das prefeituras contra o desemprego; e o pedido de elaboração de uma lei de incentivos fiscais unificada para as empresas, acompanhada da redução de impostos, como o ISS e o ICMS, com o objetivo de atrair empresas para o sul do estado.

\section{CONSIDERAÇÕES FINAIS}

A mais proeminente proposta de concertação regional já articulada no Sul Fluminense, a despeito de fracassar em sua prerrogativa de delinear uma espécie de posicionamento estratégico da região diante das pressões de uma economia progressivamente globalizada, favoreceu a retórica de comprometimento com interesses ditos supramunicipais, ajudando, assim, a extrapolar a tradicional ótica da competitividade interna entre seus municípios. Contudo, algumas considerações podem e devem ser feitas no sentido de gerar reflexões futuras sobre as políticas de desenvolvimento regional (do Sul Fluminense, em especial). Todas são fundamentadas nas evidências apresentadas no decorrer desta discussão.

1. Em primeiro lugar, este texto teve o compromisso de propor o avanço das abordagens sobre trajetórias de desenvolvimento e mudança institucional em regiões industriais brasileiras. É fundamental enfatizar essa tendência de análise do contexto propriamente subnacional, porque a produção ainda é relativamente ínfima. Dos casos citados, o ABC paulista possui maior volume de produção e, justamente por isso, serviu como referência para o debate. As comparações, no entanto, devem se limitar à presença da indústria automobilística e à trajetória de esvaziamento e recuperação ou revitalização regional via articulação bem executada entre público e privado. Não é justificável comparar uma experiência concluída e bem-sucedida com outra que acabou engessada. O Sul Fluminense, conforme foi abordado, tem apresentado trajetórias díspares entre seus municípios e encontra, possivelmente na indústria automobilística e na siderurgia, atividades industriais com efeitos distintos sobre as localidades. Isso ainda merece uma investigação mais detalhada, sobretudo no caso da siderurgia e da organização da sua cadeia produtiva, com as ações entendidas como estratégicas para a CSN e os efeitos que tendem a suscitar em Volta Redonda, nos próximos anos. Já a menção às cidades siderúrgicas norte-americanas vale pelo fato de elas conseguirem expandir sua escala de desenvolvimento a partir de um nível mais localizado para outro mais regionalizado. Etambém, como informa a bibliografia mobilizada, por terem se desvinculado da paisagem siderúrgica (em termos ambientais e econômicos).

2. Ademais, é na crise atravessada por Volta Redonda (falências industriais, demissões, reduções no seu fluxo comercial, etc.) que se encontra a origem de um discurso mais comprometido com projetos de abrangência regional. Isso, naturalmente, induz à constatação de que a inclinação para o processo de concertação atendia mais à necessidade particular do município em estabelecer novos mecanismos de captação de recursos que reduzissem seu grau de dependência (e dos municípios de Barra Mansa e Pinheiral) em relação à Companhia Siderúrgica Nacional.

3. Nos casos de Resende, Porto Real e Itatiaia, a adesão mostrou-se menos intensa, ou pela presença pouco significativa e amadurecida de lideranças sindicais, empresariais e políticas (caso de Porto Real e Itatiaia) ou porque a história já anunciava, a partir da chegada das montadoras, para onde tenderia, a partir de então, o fluxo do desenvolvimento do Sul Fluminense (Resende). A relevância alcançada por Volta Redonda a partir da década de 1940, que o alçou à condição de maior centro de transformação da estrutura econômica do país, pelo caráter vital da produção siderúrgica para a indústria nacional, foi progressivamente minimizada pelo novo ciclo de prosperidade anunciado para os seus vizinhos. Esse veio de interpretação sugere estar em andamento um processo não de mudança, mas de deslocamento institucional, transferindo a centralidade para um novo conjunto de municí- 
pios direcionados para a cadeia automobilística.

4. Por fim, o vínculo entre Volta Redonda e CSN institui limitações estruturais, que comprometem planos de desenvolvimento mais regionalizado e descentralizado. São limitações porque, após décadas de predomínio de um modelo praticamente fundado na atuação de uma grande unidade de produção verticalmente organizada, são enormes as dificuldades de transgredi-lo. Haja vista o esvaziamento do cinturão de fornecedores, cujo foco era reforçar o vínculo das empresas locais com a Companhia, pela qual acabaram vitimadas pela decisão de rompimento unilateral. Ações coletivas recentes, como o "Fórum Demissão Zero”, deixam dúvida se, de fato, refletem a capilaridade de associações, sindicatos e movimentos sociais. Pouco provável de conduzir à mudança institucional, essa mobilização ao menos indica a ocorrência de um aprendizado, acompanhado do aparecimento de novas oportunidades políticas, bem como da chance de reconfigurar as estruturas locais frente aos imperativos da globalização.

Recebido para publicação em 20 de dezembro de 2011 Aceito em 29 de maio de 2012

\section{REFERÊNCIAS}

A CRISE sacode a cidade do aço, O Globo, Rio de Janeiro, 21 out., 1983.

ABRAMOVAY, Ricardo. Desenvolvimento e instituições: a importância da visão histórica. In: ARBIX, Glauco; ZILBOVICIUS, Mauro; ABRAMOVAY, Ricardo (Org.). Razões e ficções do desenvolvimento. São Paulo: EDUSP, 2001. p. 165-177.

ABRÚCIO, Fernando L.; SOARES, Marcia M. Redes Federativas no Brasil: cooperação intermunicipal no Grande ABC. São Paulo: Fundação Konrad Adenauer, 2001.

AMARAL, C. Reestruturação sócio-produtiva e ações de promoção do desenvolvimento local na microrregião do promoção do desenvolvimento local na microrregiáo do
Vale do Paraíba (RJ). Rio de Janeiro: Núcleo de assessoria, planejamento e pesquisa (NAPP), 2001. Disponível em: www.iets.org.br/biblioteca/Reestruturacao_socio produtiva e acoes de promocao do desenvolvimento local na microrregiào_do_vale_do_Paraiba_RJ.PDF. Acesso em : $\overline{4}$ jan. 2013.

ARBIX, Glauco. Guerra fiscal e competição intermunicipal por novos investimentos no setor automotivo. Dados, Rio de Janeiro, v. 43, n. 1, p. 5-43, 2000.

BAGNASCO, A. A teoria do desenvolvimento e o caso italiano. In: ARBIX, Glauco; ZILBOVICIUS, Mauro; ABRAMOVAY, Ricardo (Org.). Razões e ficções do desen- volvimento. São Paulo: EDUSP, 2001. p. 349-363.

BANDEIRA, Pedro. Participação, articulação de atores sociais e desenvolvimento regional. Texto para Discussão, n. 630, fev., 1999. Disponível em: www.unc.br/mestrado/ mestrado_materiais/texto_pedro_bandeira_n.630.pdf. Acesso em: 4 jan. 2013.

BOURDIN, Alain. A questão local. Rio de Janeiro: DP\&A, 2001. BRASIL. Ministério da Integração Nacional. Carta Sul Fluminense. Ciclo de Eventos sobre o Desenvolvimento. Brasília, 2008. Disponível em: www.integracao.gov.br/ desenvolvimentoregional/desenvolvimentosulfluminense/ index.a. Acesso em: 4 jan. 2013.

BRESCIANI, Luís; KLINK, Jeroen; LÉPORE, Wendell. Câmara Regional do ABC - produção e reprodução do capital social na região do Grande ABC paulista. Economia \& gestão, Belo Horizonte, v. 6, n. 13, maio, p. 1-18, 2006. Disponível em: http://periodicos.pucminas.br/ index.php/economiaegestao/article/view/29/124. Acesso em: 4 jan. 2013.

CARDOSO, Adalberto M. Trabalhar, verbo transitivo: destinos profissionais dos deserdados da indústria automobilística. Rio de Janeiro: FGV, 2000.

COELHO, Franklin. Consórcios regionais de desenvolvimento: os mercados regionais no estado do Rio de Janeiro. Santiago (Chile): Comisión Econômica Para América Latina Y El Caribe (CEPAL), 2000. Disponível em: www.eclac.org/publicaciones/xml/9/6069/lcr1982e.pdf. Acesso em: 4 jan. 2013.

CONCEIÇÃO, Jefferson J. ABC: região em mudança. Teoria e debate, São Paulo, n. 37, fev./abr., p. 32-37, 1998.

COOKE, Philip. Keeping to the high road: learning, reflexivity and associative governance in regional economic development. In: (Ed.) The rise of the rustbelt. Londres: UCL Press, 1995. p. 231-245.

CRISE Econômica leva à união de todos. Diário do Vale, Volta Redonda, 6 ago.,1997.

CUNHA, L. B. Região do Médio Vale do Paraíba, uma categoria para ser afirmada. Boletim da Economia Fluminense, Rio de Janeiro, n. 5, 2001.

DEITRICK, S.; BEAUREGARD, R. A. From front-runner to also-ran - the transformation of a once-dominant industrial region: Pennsylvania, USA. In: COOKE, Philip (Ed.). The rise of the rustbelt. Londres: UCL Press, 1995. p. 52-71.

DIÁRIO DO VALE, Volta Redonda, 17 ago., 1997.

, Volta Redonda, 21 out., 1998.

DIAS, Luciano; SIMÕES, Dicler; SCHÜFFNER, Cláudia. CSN tem lucro de 450 milhões, o maior da sua história. $O$ Globo, Rio de Janeiro, 19 mar., 1998.

DURÃO, Mariana. No ABC Fluminense, negócios de R\$ 4,7 bi. O Globo, Rio de Janeiro, 23 out., 2011.

GARCIA, Sandro. Trabalho, Sindicatos e o cenário global: a fábrica da General Motors em Gravataí (Versão Preliminar). In: CONGRESSO BRASILEIRO DE SOCIOLOGIA, 14., 2009, Rio de Janeiro. Anais... Rio de Janeiro: UERJ, 2009a.

Global e local: o pólo automobilístico de Gravataí. São Paulo: Annablume, 2009b.

GUIMARÃES, Nadya; MARTIN, Scott. Descentralização, equidade e desenvolvimento: atores e instituições locais. In: _. (Org.) Competitividade e desenvolvimento: atores e instituições locais. São Paulo: Senac, 2001.p. 11-32.

HELLER, Patrick. Social capital as a product of class mobilization and state intervention: industrial workers in Kerala, India. World Development, Quebec, v. 24, n. 6, p. 1055-1071, jun., 1996. 
HIRST, Paul. Associative democracy: new forms of economic and social governance. Amherst: University of Massachusetts Press, 1994. 232 p.

INSTITUTO BRASILEIRO GEOGRÁFICO E ESTATÍSTICO (IBGE). Produto Interno Bruto dos Municípios Brasileiros: 2005-2009. Rio de Janeiro: IBGE, 2011.

JORNAL DO BRASIL, Rio de Janeiro, 14 jul., 1979.

KLINK, Jeroen J. A cidade-região: regionalismo e reestruturação no grande ABC paulista. Rio de Janeiro: DP\&A, 2001.

LEITÃO, Mírian. Coluna Panorama Econômico. O Globo, Rio de Janeiro, 22 abr., 1997.

LEITE, Marcia. Trabalho e sociedade em transformação: mudanças produtivas e atores sociais. São Paulo: Fundação Perseu Abramo, 2003.

LIMA, Rephael J. A reinvenção de uma cidade industrial Volta Redonda e o pós-privatizacão da Companhia Siderúrgica Nacional (CSN). 2010. 277 f. Tese (Doutorado em Sociologia) - Universidade Federal do Rio de Janeiro, Rio de Janeiro, 2010

Entrevista realizada com o ex-secretário de planejamento de Barra Mansa na sede do MetalSul. [maio 2008]. Entrevistador: Raphael Jonathas da Costa Lima. Volta Redonda, Rio de Janeiro, 2008.

Entrevista realizada com o secretário de desenvolvimento econômico e turismo na prefeitura de Volta Redonda. [set. 2010]. Entrevistador: Raphael Jonathas da Costa Lima Volta Redonda, Rio de Janeiro, 2008.

Entrevista realizada com o superintendente executivo da Agência de Desenvolvimento Econômico do Médio Paraíba - ADEMP na sede da ACIAP-VR. [maio 2009]. Entrevistadores: Raphael Jonathas da Costa Lima, Volta Redonda, Rio de Janeiro, 2009.

LOCKE, Richard. Remaking the italian economy. New York: Cornell University, 1995.

; JACOBY, Wade. The Dilemmas of diffusion social embeddedness and the problems of institutional change in Eastern Germany. Politics \& society, v. 25, n. 1 p. 34-65, mar., 1997.

MANGABEIRA, Wilma. Dilemas do novo sindicalismo: democracia e política em Volta Redonda. Rio de Janeiro: Relume Dumará, ANPOCS, 1993.

MARKUSEN, A. Mudança econômica regional segundo o enfoque centrado no ator. In: DINIZ, Clélio; LEMOS, Mauro B. (Org.). Economia e Território. Belo Horizonte: Editora UFMG, 2005. p. 57-75.

MONTEIRO, G.T. Sindicato dos metalúrgicos de Volta Redonda: 50 anos brasileiros. Rio de Janeiro: FSB Comuคे nicações, 1995

MOREL, Regina L. A ferro e fogo: construção e crise da "família siderúrgica" - o caso de Volta Redonda (1941 ¿ 1968). 1989. 506 f. Tese (Doutorado em Sociologia) Universidade de São Paulo, 1989

VOLTA REDONDA (RJ). Parque Industrial do Contorno. Volta Redonda: Secretaria Municipal de Desenvolvimento Econômico e Turismo, 2011. Disponível em www.smdet.com.br/conteudo.php?cod=28. Acesso em: 4 jan. 2013.

Parque Industrial João Pessoa Fagundes. Secretaria Municipal de Desenvolvimento Econômico e Turismo, ANO. Disponível em: www.smdet.com.br/ conteudo.php?cod=31. Acesso em: 17 jan., 2013.

Parque Industrial do Roma. Secretaria Municipal de Desenvolvimento Econômico e Turismo, ANO. Dis ponível em: www.smdet.com.br/conteudo.php?cod=27. Acesso em: 19 jan., 2013.
Secretaria de Desenvolvimento Econômico e Turismo. Disponível em: www.smdet.com.br. Acesso em: 15 jan. 2013.

PEREIRA, Sérgio E. M. Sindicalismo e privatização: o caso da Companhia Siderúrgica Nacional. 2007. 282 f. Tese (Doutorado em Sociologia) - Instituto de Filosofia e Ciências Humanas, Universidade Federal do Rio de Janeiro, Rio de Janeiro, 2007.

PIKE, Andy; RODRIGUEZ-POSE, Andres; TOMANEY, John. Local and regional development. New York: Routledge, 2006.

PIQUET, Rosélia. Cidade-empresa: presença na paisagem urbana brasileira. Rio de Janeiro: Jorge Zahar, 1998.

PUTNAM. Roberto. Comunidade e democracia: a experiência da Itália moderna. Rio de Janeiro: FGV, 1996.

REVISTA ALIANCA EMPRESARIAL. Volta Redonda: Associação Comercial, Industrial e Agropastoril de Volta Redonda, jun., 2001.

RAMALHO, Jose R. Novas conjunturas industriais e participação local em estratégias de desenvolvimento. $D a-$ dos: revista de ciências sociais, Rio de Janeiro, v. 48, n. 3 , p. 147-178, jul./set., 2005. Disponível em: http:// redalyc.uaemex.mx/pdf/218/21848302.pdf. Acesso em: 4 jan. 2013.

; SANTANA, M. A. Promessas e efeitos práticas da implantacão da indústria automobilística no Sul Fluminense. In: ENCONTRO ANUAL DA ANPOCS, 25., 2001, Caxambu. Anais... Caxambu: ANPOCS, 2001.

; RODRIGUES, Iram J.; CONCEIÇÃO, Jefferson. Reestruturação industrial, sindicato, território e alternativas políticas em momentos de crise na região do $\mathrm{ABC}$ em Sã̃o Paulo, Brasil. Revista crítica de ciências sociais, Coimbra, n. 85, p. 147-167, jun., 2009. Disponível em: h t t p : / / d i a ln e t. unirioja.es / s e r v le t/ articulo?codigo $=3285004$. Acesso em: 4 jan. 2013 .

; RODRIGUES, Iram J. Sindicato, Crise Econômica e Estratégias Regionais - novas dimensões da participação política no ABC Paulista. Cadernos CRH, Salva-
dor, v. $23, \quad$ n. 59, 2010. Disponível em: www.cadernocrh.ufba.br/viewarticle.php?id=765. Acesso em: 4 jan. 2013.

RELATÓRIO Mercovale referente ao ano de 1997: movimento ética na política de Volta Redonda. Volta Redonda: MEP-VR, 1998.

SANTOS, Rodrigo S. A construção social da região: desenvolvimento regional \& mobilização sócio-política no Sul Fluminense. 2006. 233f. Dissertacão (Mestrado em Sociologia) - Universidade Federal do Rio de Janeiro, Rio de Janeiro, 2006.

SCOTT, Allen J. A perspective of economic geography. Journal of economic geography, Oxford, v. 4, n. 5, p. 479499, nov., 2004.

TENDLER, Judith. Bom governo dos trópicos: uma visão crítica. Rio de Janeiro: Revan, 1998.

TURNO de revezamento de 8 horas na CSN. Jornal A Voz da Cidade, Barra Mansa, 2 fev. 2009. 


\section{INTEGRATED STRATEGIES FOR REGENERATION IN INDUSTRIAL REGIONS: an approach to the post-1990s scenario in southern Rio de Janeiro state}

\section{Raphael Jonathas da Costa Lima}

The purpose of this article is to discuss the constitution of new institutional arrangements in industrial regions with steel mills and automotive plants. This analysis has to do with initiatives forged in economically depressed contexts caused by factories' either moving away or closing, restructuring of production and downsizing. Its focus is to describe strategies and mobilizations created inside public and private organizations with a prospect of revitalizing these degraded areas. This discussion deals with the scenario in southern Rio de Janeiro State, a region that in recent years has witnessed discourse in favor of regionalization and cooperation among its municipalities. This article shows that the region has become more and more polarized between an expanding extension led by the automobile industry and another which has stagnated due to the dependence on the activity of a great economic agent. The conclusion is that this leads to structural limitations and jeopardizes the plans for more integrated development in the region.

KEY wORDs: Dialog. Regional development. Governance. Restructuring of production. Revitalization.

\section{STRATÉGIES INTÉGRÉES DE RÉHABILITATION DE RÉGIONS INDUSTRIELLES: rapprochement de la conjoncture des années post 1999 dans le Sud de l'Etat de Rio de Janeiro}

\section{Raphael Jonathas da Costa Lima}

Cet article se veut de discuter de la mise en place de nouveaux accords institutionnels dans des régions ayant un profil industriel et dont la caractéristique est la présence de secteurs tels que la sidérurgie et l'industrie automobile. Lanalyse se penche sur des initiatives forgées dans des contextes économiquement touchés par des processus de départ et de fermeture d'industries, de restructuration de la production et de réduction des effectifs. L'accent est mis sur la description des stratégies et des mobilisations au sein des organisations publiques et privées visant une perspective de revitalisation de ces zones dégradées. La discussion porte sur la conjoncture du sud de l'état de Rio, région où un discours en faveur de la régionalisation et d'une coopération entre municipalités s'est renforcé au cours des dernières années. Létude montre que la région se partage progressivement entre une étendue en phase d'expansion grâce à l'industrie automobile et une autre partie plongée dans le marasme à cause de sa dépendance envers l'activité d'un agent économique important. On en arrive à la conclusion que tous ces éléments finissent par instituer des limitations structurelles et compromettre les projets d'un développement plus intégré pour la région.

MOTS-CLÉs: Concertation. Développement régional. Gouvernance. Restructuration productive. Revitalisation.

Raphael Jonathas da Costa Lima - Doutor em Sociologia pela Universidade Federal do Rio de Janeiro (UFRJ). Professor do Departamento Multidisciplinar da Universidade Federal Fluminense (UFF). Lidera o Grupo de Estudos em Desenvolvimento do Sul Fluminense (GEDESF), desenvolvendo pesquisas nas áreas de Sociologia do Trabalho e Desenvolvimento Regional. Sua mais recente publicação é: Articulação e reorganização sociopolítica em Volta Redonda no pós-privatização da Companhia Siderúrgica Nacional. In: José Ricardo Ramalho; Alexandre Fortes. (Org.). Desenvolvimento, Trabalho e Cidadania Baixada e Sul Fluminense. 1ed. Rio de Janeiro: 7 Letras, 2012, p. 203-224. 
